\title{
Isolation and characterization of side population cells from the human ovarian cancer cell line SK-OV-3
}

\author{
ZHENGYI RUAN $^{1}$, JIANHUA LIU $^{1}$ and YANPING KUANG ${ }^{2}$ \\ Departments of ${ }^{1}$ Gynecology and ${ }^{2}$ Assisted Reproduction, Shanghai Ninth People's Hospital Affiliated \\ to Shanghai Jiao Tong University School of Medicine, Shanghai 200011, P.R. China
}

Received October 16, 2014; Accepted September 29, 2015

DOI: $10.3892 /$ etm.2015.2836

\begin{abstract}
Ovarian cancer (OC) is the most malignant type of gynecological tumor due to its high recurrence rate following initial treatment. Previous studies have indicated that cancer stem cells (CSCs) may be a potential cause underlying the high proportion of recurrence. Side population (SP) cells isolated from cancer cell lines have been shown to exhibit characteristics associated with CSCs, but studies on SP cells in human ovarian SK-OV-3 cell line are limited. In the present study, the SP cell fraction (4.83\% of the total cell population) was isolated using flow cytometry, and analyzed by immunocytochemical analysis and reverse transcription-quantitative polymerase chain reaction. The results showed that SP cells exhibited a high mean fluorescence intensity for CD44, a CSC marker, in addition to elevated expression of the CSCs-associated genes, ATP-binding cassette sub-family G member 2 and Nestin. These findings indicated the stem cell-like features of the SP cells. Furthermore, a colony formation test showed that the isolated SP cells possessed a marked capacity for self-regeneration and proliferation. In addition, a cell cycle assay involving cisplatin indicated that the SP cells were strongly resistant to chemotherapy. In conclusion, the present results suggested that SP cells isolated from the SK-OV-3 cell line exhibited properties typically associated with CSCs. Therefore, the isolated SP cells may be used to provide novel insight into potential therapies against OC.
\end{abstract}

\section{Introduction}

Ovarian cancer (OC) is considered to be the most lethal type of adenocarcinoma among gynecological cancers (1). Epithelial malignancy is the leading cause of OC (2), and the 5-year survival rate of $\mathrm{OC}$ patients with epithelial malignancy is

Correspondence to: Dr Yanping Kuang, Department of Assisted Reproduction, Shanghai Ninth People's Hospital Affiliated to Shanghai Jiao Tong University School of Medicine, 639 Zhizaoju Road, Shanghai 200011, P.R. China

E-mail: kuangyanp@126.com

Key words: human ovarian cancer, side population cells, cancer stem cells, SK-OV-3 reportedly $<30 \%$ (3). Although the pathogenesis of OC is extensively studied, its precise causes remain unknown. It has been reported that infertile women that ovulate incessantly are at a high risk of developing OC (4). Furthermore, a number of genetic causes have been proposed, including the specific genes BRCA1 and BRCA2, in addition to genes for hereditary nonpolyposis colorectal cancer (5). Symptoms of OC may be subtle and $>70 \%$ of patients have already reached a terminal stage of cancer at diagnosis (6). Late diagnosis also increases the likelihood of OC recurrence following initial treatment, and increases the risk of eventual mortality $(3,7)$.

Numerous approaches have been suggested for the diagnosis and management of OC. Physical examination combined with a blood test and transvaginal ultrasound examination have been used to detect the cancer at an early stage (8). Common methods of OC management include surgical tumor resection, radiation therapy and chemotherapy (9). Despite advancements in these detection and management techniques, the prognosis of OC has not improved substantially and an increasing rate of OC recurrence is observed (10). The recently proposed hypothesis of cancer stem cells (CSCs) may provide a promising approach for the treatment of OC (11).

CSCs are a population of stem-like cells that possess the tumorigenic capability to self-renew and differentiate into multiple cell types within a tumor (12). CSCs were initially reported by Bonnet and Dick (13) in 1997 and were proposed as an explanation for the apparent heterogeneity of cancer cells (14). As CSCs are able to differentiate into a variety of cancer cells (15), the isolation of CSCs in tumors and inhibition of their growth are significant for cancer therapy. To date, a number of procedures for CSC isolation have been reported, including fluorescence-activated cell sorting, which employs fluorescent antibodies as markers on the cell surface (16), as well as functional approaches of side population (SP) cell analysis based on flow cytometry (FCM), which is performed according to the CSC characteristics (such as possessing the tumorigenic capability to self-renew and differentiate into multiple cell types within tumors) (17). In graphs produced by FCM analysis, SP cells present as a distinct subpopulation, indicated by an area of low fluorescence intensity (18). SP cells are identified by their ability to transport Hoechst 33342 dye through verapamil-sensitive ATP-binding cassette (ABC) transporters (19).

To date, a number of studies have investigated the role of SP cells in OC (20-22). However, SP cells isolated from 
SK-OV-3, a key epithelial OC cell line that was first identified by Provencher et al in 2000 (23), have not been extensively studied. In the current study, SP cells extracted from SK-OV-3 cell lines were sorted and characterized in order to isolate CSCs associated with OC. In isolated SP cells, the levels of adhesion and anti-apoptotic activity, the expression of CSC-associated genes, drug susceptibility and the capability of colony formation compared with non-SP cells were investigated.

\section{Materials and methods}

Materials. Human SK-OV-3 OC cells were obtained from the Cell Bank of the Chinese Academy of Sciences (Beijing, China). Fetal bovine serum (FBS), McCoy's 5A medium, Hoechst 33342 (no. H21492) and TRIzol reagent were purchased from Thermo Fisher Scientific, Inc. (Rockville, MD, USA). In addition, trypsin-ethylenediaminetetraacetic acid (trypsin-EDTA, $0.25 \%$ ), verapamil hydrochloride (VRP) and propidium iodide (PI) were purchased from Sigma-Aldrich (St. Louis, MO, USA). The FastQuant RT kit (no. KR106) and Super Real PreMix Plus (SYBR Green) kit were purchased from Tiangen Biotech Co.,Ltd. (Beijing, China). Cisplatin (CDDP) was purchased from Selleck Chemicals (Houston, TX, USA). Fluorescein isothiocyanate (FITC)-conjugated mouse anti-human CD44 (cat. no. 555478) and FITC mouse $\operatorname{IgG} 2 \mathrm{~b} \kappa$ isotype (cat. no. 555742) antibodies were purchased from BD Biosciences (Sparks, MD, USA). Cell Counting kit-8 (CCK-8) was obtained from Dojindo Laboratories Co., Ltd. (Kumamoto, Japan), and the crystal violet staining solution was obtained from Beyotime Institute of Biotechnology (Shanghai, China).

Cell culture. SK-OV-3 cells were cultured in McCoy's 5A medium containing 10\% FBS, 100 units $/ \mathrm{ml}$ penicillin and $100 \mu \mathrm{g} / \mathrm{ml}$ streptomycin (Gibco; Thermo Fisher Scientific, Inc., Waltham, MA, USA) in $5 \% \mathrm{CO}_{2}$ at $37^{\circ} \mathrm{C}$, and subcultured every three days according to a ratio of original medium to fresh medium of 1:3 (v:v).

SP cell sorting and analysis. SK-OV-3 cells were cultured to reach a number of $1 \times 10^{8}$ cells, and then a single-cell suspension of $1 \times 10^{6} \mathrm{cell} / \mathrm{s} / \mathrm{ml}$ was prepared via digestion using $0.25 \%$ trypsin-EDTA. The cells were then stained with Hoechst 33342 (3 $\mu \mathrm{g} / \mathrm{ml}$ ) with $200 \mu \mathrm{mol} / \mathrm{l} \mathrm{VRP} \mathrm{(which} \mathrm{is} \mathrm{an} \mathrm{inhibitor} \mathrm{of}$ certain verapamil-sensitive $\mathrm{ABC}$ transporters) as the control group, or without VRP as the test group (24), respectively. Next, the two groups were cultured in a water bath at $37^{\circ} \mathrm{C}$ for $90 \mathrm{~min}$ in the dark and were homogeneously agitated every $20 \mathrm{~min}$. Subsequently, the cell suspension was centrifuged at $400 \mathrm{x}$ g for $10 \mathrm{~min}$ at room temperature, and the sedimentary cells were washed using pre-cooled phosphate-buffered saline (PBS) and suspended in PBS with $2 \% \mathrm{FBS}$ at $4^{\circ} \mathrm{C}$. PI, an intercalating agent and fluorescent molecule, was added and used to differentiate necrotic, apoptotic and live cells (25). Following filtration using a 400 mesh strainer $(0.0374 \mathrm{~mm})$, the cells were analyzed and sorted by FCM using a MoFlo system (Dako, Glostrup, Denmark) with $350 \mathrm{~nm}$ (UV light) as the excitation wavelength and $450 / 675 \mathrm{~nm}$ (Hoechst blue/red) as the detected wavelength. The cells inside the area of low-Hoechst red and low-Hoechst blue without VRP were identified as SP cells, and the SP percentage was further calculated.
Immunocytochemical analysis. CD44 antigen is a type of homing cell adhesion molecule involved in cell-cell interactions, adhesion and migration (26). In order to assess the expression of CD44 in SP and non-SP cells isolated from SK-OV-3 cells, the cells were digested using trypsin-EDTA and suspended in McCoy's 5A medium to obtain single-cell suspension with the concentration of $1 \times 10^{6} / \mathrm{ml}$. Subsequently, $5 \mu \mathrm{l}$ FITC mouse anti-human CD44 or FITC mouse IgG2b $\kappa$ isotype control antibodies were added to $100 \mu 1 \mathrm{SP}$ or non-SP cell suspension. Following a $15-\mathrm{min}$ incubation at $37^{\circ} \mathrm{C}$, the volume of the cell suspension was adjusted to $500 \mu \mathrm{l}$ by adding PBS. Finally, the mean fluorescence intensity (MFI) of the SP and non-SP cells were recorded and analyzed using a FACSCalibur flow cytometer (BD Biosciences).

Reverse transcription-quantitative polymerase chain reaction (RT-qPCR). The SP and non-SP cells were selected and washed twice with PBS. To isolate total RNA, $1 \mathrm{ml}$ TRIzol was added and the solution was mixed homogeneously for $10 \mathrm{~min}$. The mixture was then transferred into 1.5-ml Eppendorf (EP) tubes with $200 \mu 1$ chloroform. After 15-min agitation, the EP tubes were centrifuged at $12,000 \mathrm{x} \mathrm{g}$ for $15 \mathrm{~min}$ at $4^{\circ} \mathrm{C}$. The supernatant was transferred to fresh EP tubes and mixed with isopycnic isopropanol for $15 \mathrm{sec}$. Further centrifugation was conducted $\left(4^{\circ} \mathrm{C}, 10 \mathrm{~min}, 12,000 \mathrm{x} \mathrm{g}\right)$ and the supernatant was discarded. The precipitate was washed twice with $75 \%$ ethanol and dissolved in $30 \mu 1$ diethylpyrocarbonate after drying for $\sim 15 \mathrm{~min}$ at room temperature to obtain RNA stock solution. Following isolation, the concentration of RNA was assessed using a NanoDrop 1000 spectrophotometer (Thermo Fisher Scientific, Inc., Wilmington, DE, USA) and the RNA solution was stored at $-80^{\circ} \mathrm{C}$ for further use. The isolated RNA was used as a template and was reverse transcribed into cDNA using the FastQuant RT kit, as previously described (27). Next, qPCR analysis was performed using an Mx3000P qPCR system (Stratagene; Agilent Technologies, Inc., Amsterdam, Netherlands) and the Super Real PreMix Plus (SYBR Green) kit, as follows: $1 \mathrm{~min}$ at $95^{\circ} \mathrm{C}, 40$ cycles of $10 \mathrm{sec}$ at $95^{\circ} \mathrm{C}$, and $32 \mathrm{sec}$ at $60^{\circ} \mathrm{C}$.

The primers of the target genes ATP-binding cassette sub-family G member 2 (ABCG2) and Nestin, and the reference gene glyceraldehyde 3-phosphate dehydrogenase were designed using Primer Premier 5.0 software (Premier Biosoft, Palo Alto, CA, USA) and are shown in Table I. Data were compared using the $2^{-\Delta \Delta \mathrm{Cq}}$ method.

Colony formation test. SP and non-SP cells were plated at 500 or 1,000 cells per well in 6-well plates, and cultured in McCoy's 5A medium supplemented with $10 \% \mathrm{FBS}$ at $37^{\circ} \mathrm{C}$ in $5 \% \mathrm{CO}_{2}$ for 10 days. Subsequently, the cells were washed with PBS, mixed with $4 \%$ paraformaldehyde and fixed at room temperature for $15 \mathrm{~min}$. Next, the cells were washed three times with PBS and crystal violet was added to stain the cells for $20 \mathrm{~min}$. The cells were then washed with PBS, dried at room temperature for $30 \mathrm{~min}$ and photographed (37X-V; Shanghai 5th Optical Factory, Shanghai, China).

Cell viability assay. The sorted SP and non-SP cells at logarithmic growth phase were seeded in a 96-well plate at an initial cell density of 3,000 cells per well and cultured 
Table I. Primer sequences for polymerase chain reaction assay.

\begin{tabular}{lll}
\hline Gene & \multicolumn{1}{c}{ Forward primer (5'-3') } & \multicolumn{1}{c}{ Reverse primer (5'-3') } \\
\hline ABCG2 & GCCTCACCTTATTGGCCTCA & GGCTCTATGATCTCTGTGGCTT \\
Nestin & GCGGGCTACTGAAAAGTTCC & CCAGCTTGGGGTCCTGAAAG \\
GAPDH & CGGAGTCAACGGATTTGGTCGTATTGG & GCTCCTGGAAGATGGTGATGGGATTTCC
\end{tabular}

ABCG3, ATP-binding cassette sub-family G member 2; GAPDH, glyceraldehyde 3-phosphate dehydrogenase.
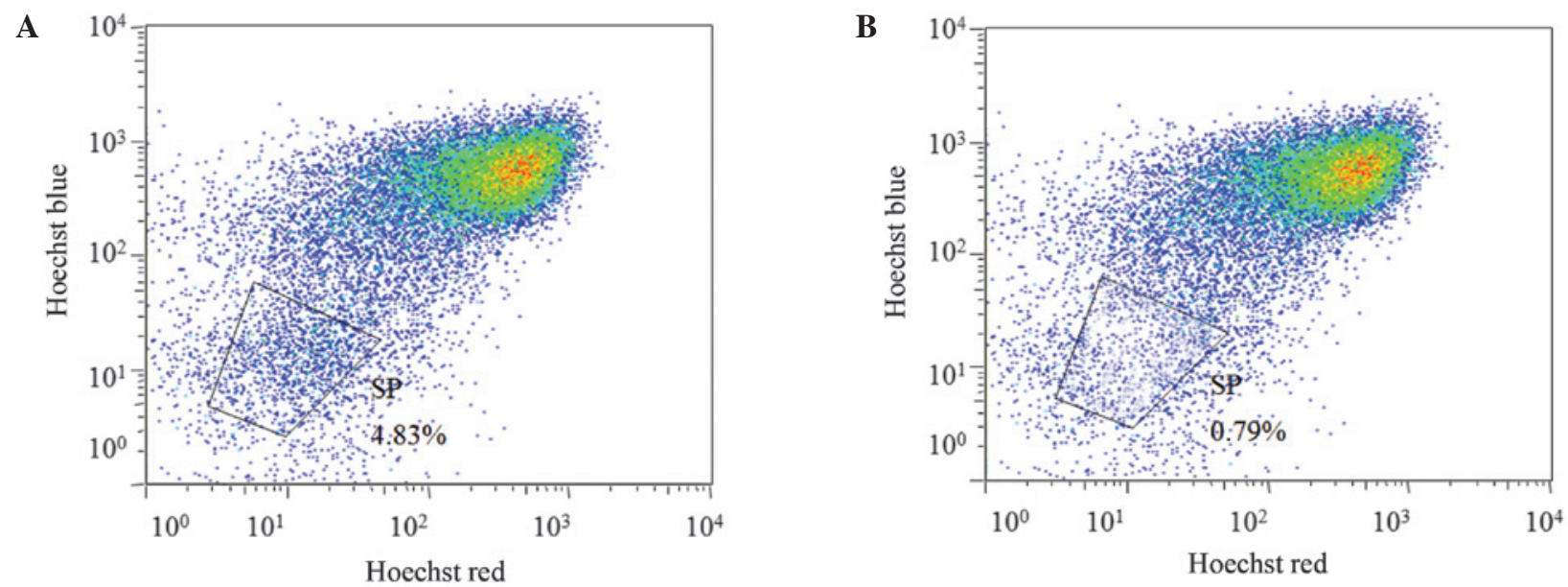

Figure 1. Identification of side population (SP) cells in the ovarian cancer cell line, SK-OV-3, treated (A) with verapamil hydrochloride (VRP) and (B) without VRP. The SP cell number was increased in the presence of VRP, which is outlined on the graph and presented as a percentage of the total cell population.

overnight in McCoy's 5A medium at $150 \mu$ l per well containing $10 \%$ FBS. CDDP was then added at various concentrations $(0,0.8,1.6,3.1,6.3,12.5,25,50,100,200$ and $400 \mu \mathrm{M})$. The cells were cultured for $48 \mathrm{~h}$ and incubated with $10 \mu \mathrm{l} \mathrm{CCK}-8$ in each well for a further $4 \mathrm{~h}$. After replacing the medium with McCoy's 5A medium, the optical density (OD) values were determined using a Cary $50 \mathrm{UV}-\mathrm{V}$ is spectrophotometer (Varian Medical Systems, Inc., Palo Alto, CA, USA) at $450 \mathrm{~nm}$. The viability of the SP and non-SP cells following CDDP treatment was assessed, and half maximal inhibitory concentration $\left(\mathrm{IC}_{50}\right)$ (28) was calculated using GraphPad Prism 5 software (GraphPad Software, Inc., La Jolla, CA, USA) as $4.32 \mu \mathrm{mol} / 1$ for SP cells and $4.26 \mu \mathrm{mol} / 1$ for non-SP cells. In addition, SP or non-SP cells treated only with solvent (normal saline) and no CDDP were defined as the corresponding control group, while plates treated without CDDP or solvent were considered to be the blank group. All groups were also treated with dimethyl sulfoxide (DMSO; Sigma-Aldrich) at the same concentration. The $100 \%$ cell viability was set based on the black group, which was treated with DMSO alone. It was calculated according to the following equation: Cell viability $(\%)=(\mathrm{ODt}-\mathrm{ODb}) /(\mathrm{ODc}-\mathrm{ODb}) \times 100(29)$, where $\mathrm{ODt}, \mathrm{ODb}$ and ODc refer to the OD value of the CDDP-treated, blank and control groups, respectively.

Drug susceptibility of SP cells. To investigate the drug susceptibility of SP cells, the influence of CDDP on the cell cycle progression of SP and non-SP cells was investigated. The SP and non-SP cells were digested by trypsin-EDTA and cultured with pre-cooled ethanol $(70 \%)$ at $4^{\circ} \mathrm{C}$ for $20 \mathrm{~h}$. After washing with PBS, the SP and non-SP cells were treated with 4.32 and $4.26 \mu \mathrm{mol} / 1 \mathrm{CDDP}$ for $48 \mathrm{~h}$, respectively. These CDDP concentrations corresponded to the $\mathrm{IC}_{50}$ values obtained from the CCK-8 assay. Next, $500 \mu \mathrm{l}$ PI/RNase staining buffer was added and the cells were incubated at $4^{\circ} \mathrm{C}$ for $30 \mathrm{~min}$. The cell cycles of treated SP and non-SP cells, as well as those of their respective control groups without CDDP, were analyzed by FCM.

Statistical treatment and analysis. The data are presented as the mean \pm standard error of the mean and were analyzed using SPSS software, version 12.0 (SPSS, Inc., Chicago, IL, USA). $\mathrm{P}<0.05$ was considered to indicate a statistically significant difference. One-way analysis of variance was used for data analysis. The results of each group were measured three times.

\section{Results}

SP cell isolation. The Hoechst-low cells from the SK-OV-3 cell line were isolated following the exclusion of apoptotic cells stained with PI, on the basis of FCM scatter signals. A distinct characteristic of SP cells is the ability to transport Hoechst 33342 from the cytoplasm to outside the cell; however, the Hoechst 33342 transfer is inhibited by VRP (19). Thus, the SP cells were defined as the cell population with distinct and unstained cells in the Hoechst-low diminished region that had been treated with VRP. The non-SP cells were identified as the major cell population dyed by Hoechst 33342. As shown in Fig. 1, the fraction of potential SP cells that were eliminated following VRP treatment among the total cell population was $4.83 \%$. 
Table II. MFI of CD44 expression in SP and non-SP cells.

\begin{tabular}{llr}
\hline Cell population & \multicolumn{1}{c}{ Antibody marker } & MFI \\
\hline Non-SP & FITC mouse IgG2b $\kappa$ isotype control & $4.04 \pm 2.9$ \\
& FITC mouse anti-human CD44 & $470.3 \pm 2.6$ \\
SP & FITC mouse IgG2b $\kappa$ isotype control & $4.01 \pm 3.2$ \\
& FITC mouse anti-human CD44 & $538.9 \pm 4.0$ \\
\hline
\end{tabular}

MFI, mean fluorescence intensity; SP, side population; FITC, fluorescein isothiocyanate.

A

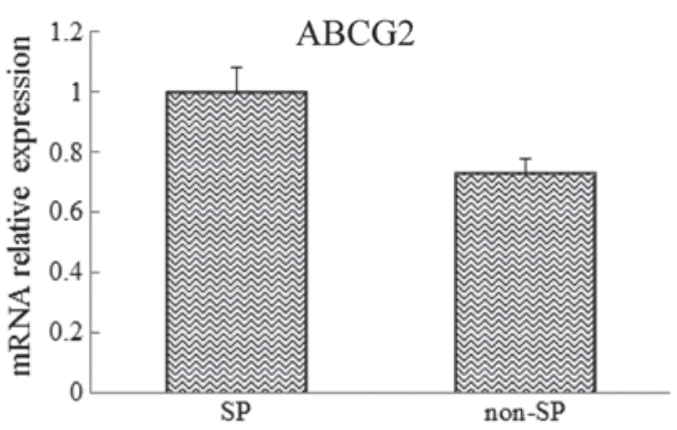

B

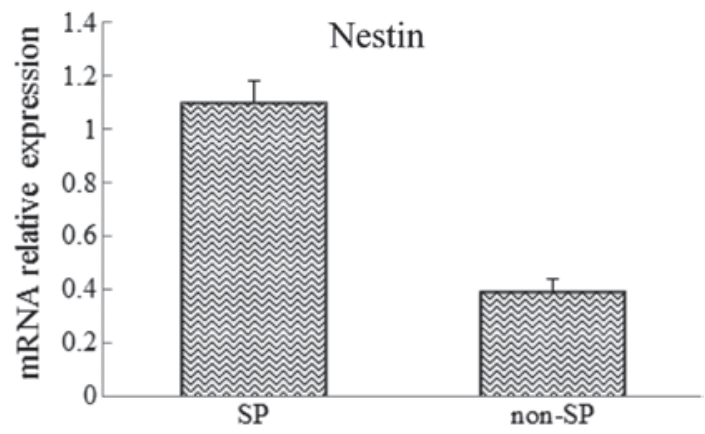

Figure 2. Expression of (A) ABCG2 and (B) Nestin in SP and non-SP cells. ABCG2, ATP-binding cassette sub-family G member 2; SP, side population.

Immunocytochemical assay. Immunofluorescence analysis uses the characteristic fluorescence of antibody markers to detect the expression of a target antigen in cells via the specific combination of an antigen and its corresponding antibody (30). In the present study, the expression of CD44 antigen, which serves a vital function in cell adhesion and exerts an anti-apoptotic effect on SP and non-SP cells, was investigated. FITC-conjugated mouse anti-human CD44 antibody was used to specifically detect the expression of the CD44 antigen. The cells were analyzed using FCM and the results are shown in Table II. Compared with the isotype, the MFI values of the SP and non-SP cells treated with FITC mouse anti-human CD44 were significantly increased. However, the higher MFI values of SP cells as compared with the non-SP cells indicated that CD44 antigen expression was more marked in the SP cells.

Analysis of the mRNA expression levels of stem cell-associated genes. The mRNA of SP and non-SP cells was extracted and analyzed using RT-qPCR to investigate the differences in the expression levels of the CSCs genes, ABCG2 and Nestin, between the SP and non-SP cells. The results showed that the mRNA expression levels of ABCG2 and Nestin were significantly increased in sorted SP cells when compared with those in the non-SP cells (Fig. 2).

Colony formation test. The tests of colony formation were repeated thrice in three parallel experiments. The results at day 10 of cultivation are shown in Fig. 3. The SP cells plated at a density of 500 or 1,000 cells per well exhibited significantly more marked colony formation ability compared with the non-SP cells, indicated that SP cells possessed a strong regenerative capability.
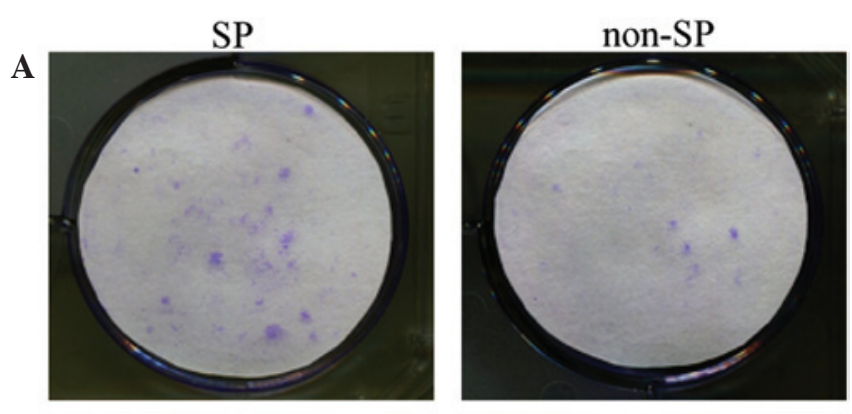

B
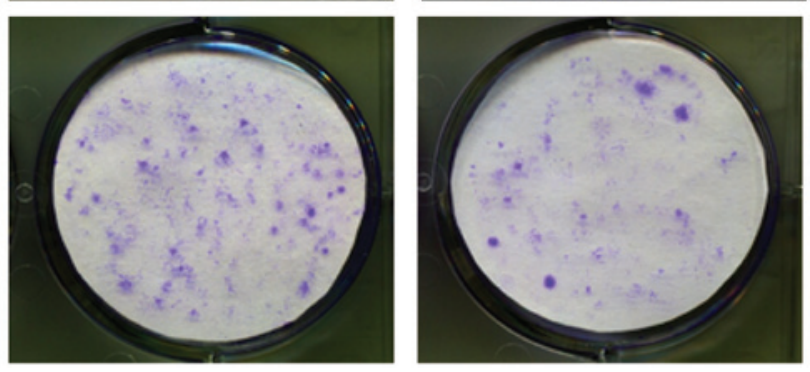

Figure 3. Colony formation of SP and non-SP cells in plates initially seeded with (A) 500 and (B) 1,000 cells (crystal violet staining). SP, side population.

Viability of CDDP-treated SP cells and CDDP-IC ${ }_{50}$. The viability of SP and non-SP cells treated at different CDDP concentrations was determined by CCK- 8 assay. The results suggest that SP cells had increased viability compared with the non-SP cells at all treated concentrations of CDDP (Fig. 4). The $\mathrm{IC}_{50}$ values were then calculated using Graph Pad Prism 5 software based on the dose response curve and were determined to be 4.32 and $4.26 \mu \mathrm{mol} / 1$ for the SP and non-SP cells, respectively. These results indicate that SP cells were more resistant to CDDP compared with the non-SP cells. 
Table III. Effect of CDDP on the proportion of SP and non-SP cells in each phase of the cell cycle.

\begin{tabular}{|c|c|c|c|c|}
\hline \multirow[b]{2}{*}{ Cell cycle phase } & \multicolumn{2}{|c|}{ Non-SP cells $(\%)$} & \multicolumn{2}{|c|}{ SP cells (\%) } \\
\hline & Untreated & CDDP-treated & Untreated & CDDP-treated \\
\hline $\mathrm{G}_{0} / \mathrm{G}_{1}$ & $14.25 \pm 0.11$ & $53.09 \pm 1.77$ & $18.02 \pm 0.23$ & $34.48 \pm 0.85$ \\
\hline S & $48.13 \pm 0.54$ & $45.36 \pm 0.55$ & $39.30 \pm 0.65$ & $50.15 \pm 0.99$ \\
\hline $\mathrm{G}_{2} / \mathrm{M}$ & $37.62 \pm 0.29$ & $1.55 \pm 1.36$ & $42.68 \pm 0.42$ & $15.37 \pm 0.14$ \\
\hline
\end{tabular}

CDDP, cisplatin; SP, side population; $\mathrm{G}_{0}$, gap $0 ; \mathrm{G}_{1}$, gap 1; S, synthesis; $\mathrm{G}_{2}$, gap 2; $\mathrm{M}$, mitosis.

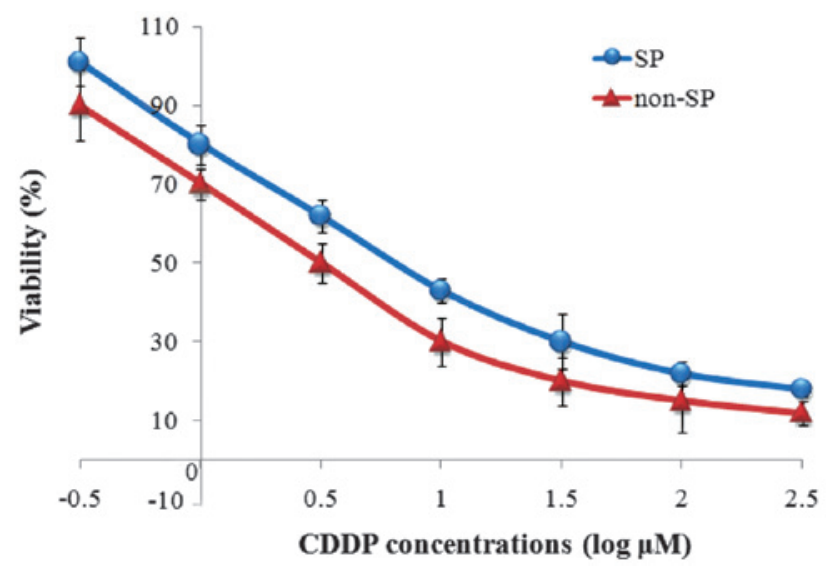

Figure 4. Effect of various CDDP doses on viability of SP and non-SP cells. $\mathrm{SP}$, side population; CDDP, cisplatin.

Effect of CDDP on SP and non-SP cells. The influence of CDDP on the cell cycles of SP and non-SP cells was investigated using FCM. The results suggested that CDDP inhibited cell reproduction more markedly in the non-SP cells compared with the SP cells, as the ratio of $\mathrm{G}_{2} / \mathrm{M}$ to total cells decreased by $95.88 \%$ in the non-SP cells, but only by $63.99 \%$ in the SP cells. These results demonstrated that the sorted SP cells had a strong proliferative capacity (Fig. 5 and Table III).

\section{Discussion}

$\mathrm{OC}$ is the leading cause of mortality among gynecological cancer types; thus, the management and treatment of $\mathrm{OC}$ patients have been widely investigated (31). Despite undergoing the typical treatment of cytoreductive surgery followed by radiotherapy and chemotherapy, $>70 \%$ of patients with OC suffer tumor recurrence and even succumb to the disease (32). Previous studies have suggested that CSCs, which exhibit the characteristics of renewal, proliferation and chemotherapy resistance, may underlie the high rate of $\mathrm{OC}$ recurrence and the general failure of current therapies (33-36). Thus, therapies targeting CSCs are required as a potential approach for reducing the recurrence rate of $\mathrm{OC}$ and prolonging the lifespan of patient. Since they were first identified by Bonnet and Dick in 1997, CSCs have been investigated and isolated using a preferred method of identification involving the use of specific makers (15,37-39). However, in the majority of solid tumors, CSCs are rare and difficult to access, and have no identifiable specific markers. In order to isolate and enrich a population of
CSCs, an SP isolation technique based on the distinct projection pattern of SP cells that efflux Hoechst 33342 dye via verapamil-sensitive $\mathrm{ABC}$ transporters has been developed (18).

A number of previous studies have investigated the function of CSCs in OC. Szotek et al (40) isolated SP cells in human OC cell lines and primary ascite cancer cells. In addition, Kobayashi et al (20) isolated SP cells from three OC cell lines (OV2008, KF28 and TU-OM-1) and then investigated the effect of paclitaxel (PTX) and CDDP combination treatment on the sorted SP cells. The results demonstrated that the SP cells proliferated despite being treated with PTX and CDDP simultaneously, which demonstrated the chemoresistance of SP cells (20). Furthermore, CSCs may be enriched in SP cells, since these cells were reported to exhibit CSC-like characteristics in OC (41). As epithelial malignancy is considered to be the leading cause of $\mathrm{OC}$, the focus of the present study was on sorting and characterizing the SP cells in the human epithelial OC cell line, SK-OV-3.

The SP cells were isolated using an FCM technique, and found to account for $4.38 \%$ of the total cell population. The CD44 antigen, a transmembrane glycoprotein, is involved in a variety of crucial cellular processes, including cell proliferation, differentiation, survival and migration (42). CD44 was hypothesized to be associated with the pathology of CSC due to its ability to enhance cellular migration and adhesion, as well as the growth and aggregation of the tumor. According to a previous study, $\mathrm{CD} 44^{+}$cells were demonstrated to be breast CSCs, with higher tumorigenicity and metastatic ability (43). CD44 has been used individually or in combination with other markers to identify CSCs in numerous tumor types, including tumors of the pancreas (44), colon (45), stomach (46) and ovaries (47). In the present study, the identification of the sorted SP cells was confirmed via CD44 antigen recognition using a FITC mouse anti-human CD44 antibody. The increased MFI values of the SP cells compared with those in the non-SP cells indicated that the sorted SP cells migrated and aggregated vigorously and were therefore a potential candidate population of OC CSCs.

This result was further verified at the gene level, by evaluating the mRNA expression levels of Nestin and ABCG2 using RT-qPCR. ABCG2, a neural stem cell gene, encodes a membrane-associated protein included in the ABC transporter, which serves a crucial function in Hoechst 33342 cellular efflux $(48,49)$. Castillo et al $(50)$ observed that the ABCG2 transporter is a significant marker of chemotherapy resistance in prostate cancer. Yanamoto et al (51) identified a positive correlation between ABCG2 expression and local 

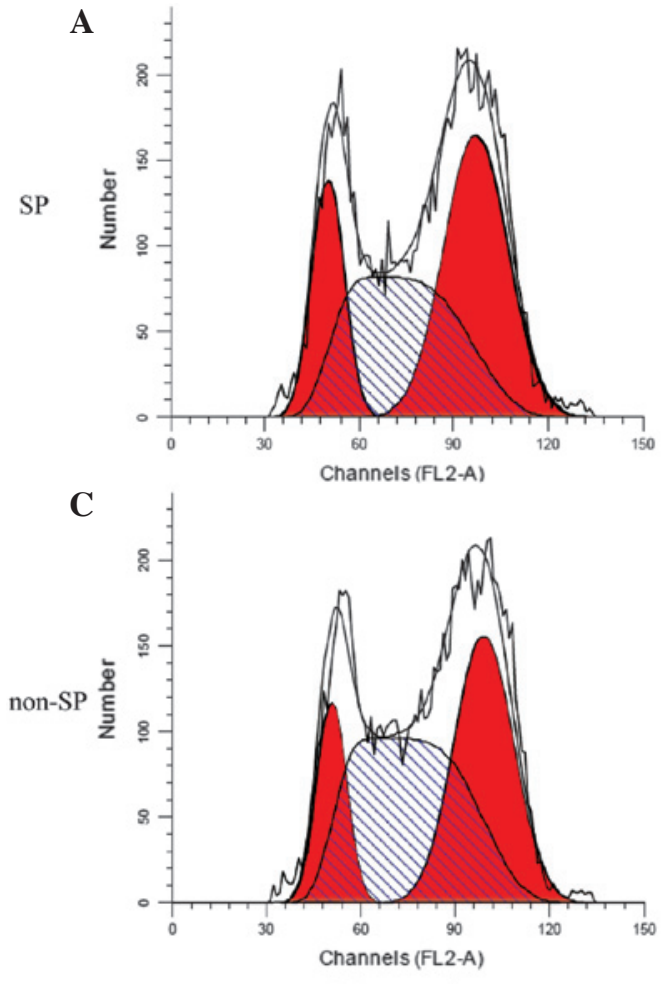

Untreated
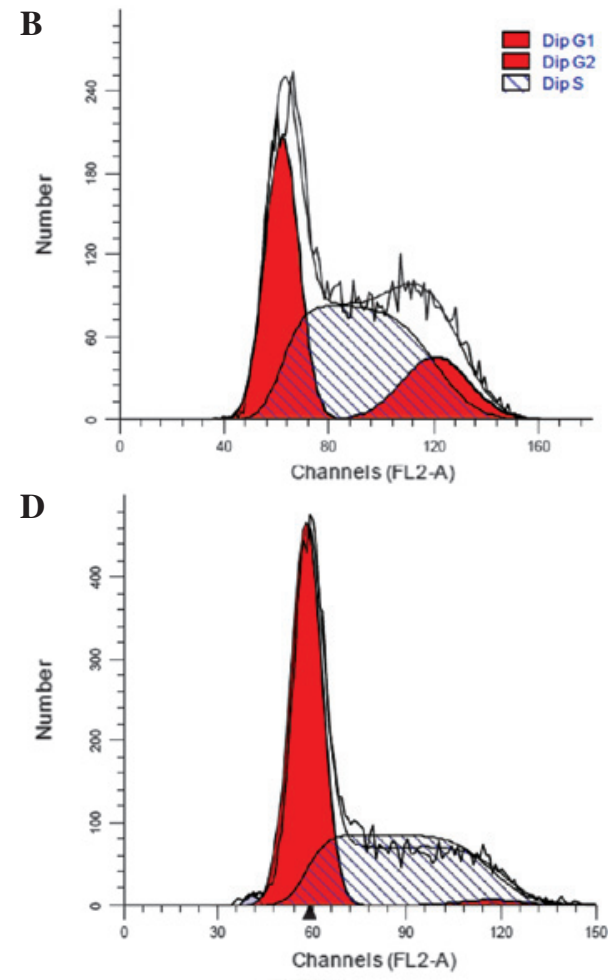

CDDP-treated

Figure 5. Effect of CDDP on the proportion of cells in each stage of the cell cycle in (A) untreated SP, (B) CDDP-treated SP, (C) untreated non-SP and (D) CDDP-treated non-SP cells, as detected by flow cytometry. 'Dip' refers to the ratio of cells during each cell cycle phase. SP, side population; $\mathrm{G}_{1}$, gap 1; $\mathrm{G}_{2}$, gap 2; S, synthesis; CDDP, cisplatin.

recurrence of tongue cancer, which was reportedly associated with CSCs. In addition, the elevation of ABCG2 expression has been observed in a number of putative CSCs. Therefore, ABCG2 was considered to be a significant marker of CSCs. Nestin was initially identified as a marker of neuroepithelial stem cells, and has been reported to be highly expressed in cells outside of the nervous tissue, including CSCs in epithelial tumors (52), breast cancer (53) and gastric cancer (54). In the present study, the expression levels of ABCG2 and Nestin were significantly increased in the SP cells compared with the non-SP cells. These results suggest that the SP cells isolated in the current study possessed properties characteristic of CSCs.

An additional fundamental characteristic of CSCs is their potential for proliferation and self-regeneration (55). In the present study, the capacity of the isolated SP cells for proliferation and self-regeneration was investigated via a colony formation test. The sorted SP and non-SP cells were cultured under identical conditions for 10 days, and the number of SP cells was found to be evidently increased compared with that of the non-SP cells in plates seeded at densities of 500 or 1,000 cells. This result is consistent with the findings of a previous study, which observed an increased colony formation capacity in SP cells compared with non-SP cells (56).

As CSCs have been recognized to be a crucial factor underlying the chemotherapy resistance of cancer tissues, the chemoresistance of the sorted SP cells against CDDP was also investigated. CDDP is a chemotherapeutic agent used in oncotherapy, which causes DNA crosslinking and ultimately induces apoptosis (57). The cellular viability of the SP and non-SP cells was decreased as the concentration of CDDP was increased. The viability of the SP cells at all treated concentrations of CDDP, as well as the corresponding $\mathrm{IC}_{50}$ values, were increased in the SP cells compared with the non-SP cells, indicating that the SP cells possessed more marked chemoresistance.

The cell cycle is defined as the entire period of cellular development, from one cell into two daughter cells after cell division and duplication. According to a previous study, the cell cycle consists of five basic stages: Gap $0\left(\mathrm{G}_{0}\right)$, a senescent phase in which cells have stopped dividing; gap $1\left(\mathrm{G}_{1}\right)$, the beginning of interphase in which cells increase in size and prepare for DNA replication; synthesis (S), the primary phase in which DNA replication occurs; gap $2\left(\mathrm{G}_{2}\right)$, the final period of interphase in which the cell grows continuously following DNA synthesis; and mitosis (M), the cell division stage in which growth is complete and cells divide (58). As the cell cycle, particularly the $\mathrm{M}$ phase, is essential for the proliferation of CSCs (59), we investigated the effect of CDDP on the cell cycle progression of the sorted SP and non-SP cells. Following CDDP treatment, the reduced proportion of non-SP cells in $\mathrm{G}_{2} / \mathrm{M}$ stage compared with the SP cells indicated that the SP cells reproduced more rapidly, and further suggested their capacity for chemoresistance. The results indicated that the sorted SP cells possessed a marked ability to proliferate and resist chemotherapy, which are characteristic properties of CSCs.

In conclusion, SP cells were isolated from the SK-OV-3 human OC cell line using FCM, and their isolation was verified by the immunocytochemical detection of the CD44 marker and evaluation of the mRNA expression levels of ABCG2 
and Nestin. The sorted SP cells exhibited a high capacity for self-regeneration, proliferation and chemotherapy resistance, which are typical features of CSCs. Therefore, the SP cells with CSC characteristics isolated in the present study may provide a novel insight into OC therapy. Further studies should be performed in order to resolve the issue of the inhibition of the growth and proliferation of SP cells, which may be more effective in treating OC than dealing with the non-SP cells.

\section{References}

1. Ruscito I, Dimitrova D, Vasconcelos I, Gellhaus K, Schwachula T, Bellati F, Zeillinger R, Benedetti-Panici P, Vergote I, Mahner S, et al: BRCA1 gene promoter methylation status in high-grade serous ovarian cancer patients-a study of the tumour bank ovarian cancer (TOC) and ovarian cancer diagnosis consortium (OVCAD). Eur J Cancer 50: 2090-2098, 2014.

2. Chen J, Wang J, Zhang Y, Chen D, Yang C, Kai C, Wang X, Shi F and Dou J: Observation of ovarian cancer stem cell behavior and investigation of potential mechanisms of drug resistance in three-dimensional cell culture. J Biosci Bioeng 118: 214-222, 2014

3. Cannistra SA: Cancer of the ovary. N Engl J Med 351: 2519-2529, 2004.

4. Purdie DM, Bain CJ, Siskind V, Webb PM and Green AC: Ovulation and risk of epithelial ovarian cancer. Int J Cancer 104: 228-232, 2003

5. Boyd J and Rubin SC: Hereditary ovarian cancer: Molecular genetics and clinical implications. Gynecol Oncol 64: 196-206, 1997.

6. Goff BA, Mandel L, Muntz HG and Melancon CH: Ovarian carcinoma diagnosis. Cancer 89: 2068-2075, 2000.

7. Meunier L, Puiffe ML, Le Page C, lali-Mouhim A, Chevrette M, Tonin PN, Provencher DM and Mes-Masson AM: Effect of ovarian cancer ascites on cell migration and gene expression in an epithelial ovarian cancer in vitro model. Transl Oncol 3: 230-238, 2010.

8. Fishman DA, Cohen L, Blank SV, Shulman L, Singh D, Bozorgi K, Tamura R, Timor-Tritsch I and Schwartz PE: The role of ultrasound evaluation in the detection of early-stage epithelial ovarian cancer. Am J Obstet Gynecol 192: 1214-1221; discussion 1221-1222, 2005.

9. Chobanian N and Dietrich CS III: Ovarian cancer. Surg Clin North Am 88: 285-299, 2008.

10. Naora $\mathrm{H}$ and Montell DJ: Ovarian cancer metastasis: Integrating insights from disparate model organisms. Nat Rev Cancer 5: 355-366, 2005.

11. Eyler CE and Rich JN: Survival of the fittest: Cancer stem cells in therapeutic resistance and angiogenesis. J Clin Oncol 26 2839-2845, 2008.

12. Klonisch T, Wiechec E, Hombach-Klonisch S, Ande SR Wesselborg S, Schulze-Osthoff K and Los M: Cancer stem cell markers in common cancers-therapeutic implications. Trends Mol Med 14: 450-460, 2008.

13. Bonnet D and Dick JE: Human acute myeloid leukemia is organized as a hierarchy that originates from a primitive hematopoietic cell. Nat Med 3: 730-737, 1997.

14. Dexter DL, Spremulli EN, Fligiel Z, Barbosa JA, Vogel R, VanVoorhees A and Calabresi P: Heterogeneity of cancer cells from a single human colon carcinoma. Am J Med 71: 949-956, 1981.

15. Al-Hajj M and Clarke MF: Self-renewal and solid tumor stem cells. Oncogene 23: 7274-7282, 2004

16. Bonner WA, Hulett HR, Sweet RG and Herzenberg LA Fluorescence activated cell sorting. Rev Sci Instrum 43: 404-409, 1972.

17. Shi GM, Xu Y, Fan J, Zhou J, Yang XR, Qiu SJ, Liao Y, Wu WZ, $\mathrm{Ji} \mathrm{Y}, \mathrm{Ke} \mathrm{AW}$, et al: Identification of side population cells in human hepatocellular carcinoma cell lines with stepwise metastatic potentials. J Cancer Res Clin Oncol 134: 1155-1163, 2008.

18. Ojha R, Jha V, Singh SK and Bhattacharyya S: Autophagy inhibition suppresses the tumorigenic potential of cancer stem cell enriched side population in bladder cancer. Biochim Biophys Acta 1842: 2073-2086, 2014

19. Yanamoto S, Kawasaki G, Yamada S, Yoshitomi I, Kawano T, Yonezawa H, Rokutanda S, Naruse T and Umeda M: Isolation and characterization of cancer stem-like side population cells in human oral cancer cells. Oral Oncol 47: 855-860, 2011
20. Kobayashi Y, Seino K, Hosonuma S, Ohara T, Itamochi H, Isonishi S, Kita T, Wada H, Kojo S and Kiguchi K: Side population is increased in paclitaxel-resistant ovarian cancer cell lines regardless of resistance to cisplatin. Gynecol Oncol 121: 390-394, 2011.

21. Chung WM, Chang WC, Chen L, Lin TY, Chen LC, Hung YC and Ma WL: Ligand-independent androgen receptors promote ovarian teratocarcinoma cell growth by stimulating self-renewal of cancer stem/progenitor cells. Stem Cell Res 13: 24-35, 2014.

22. Shah MM and Landen CN: Ovarian cancer stem cells: Are they real and why are they important? Gynecol Oncol 132: 483-489, 2014.

23. Provencher DM, Lounis H, Champoux L, Tétrault M, Manderson EN, Wang JC, Eydoux P, Savoie R, Tonin PN and Mes-Masson AM: Characterization of four novel epithelial ovarian cancer cell lines. In Vitro Cell Dev Biol Anim 36: 357-361, 2000.

24. Kaur M, Ita KB, Popova IE, Parikh SJ and Bair DA: Microneedle-assisted delivery of verapamil hydrochloride and amlodipine besylate. Eur J Pharm Biopharm 86: 284-291, 2014.

25. Lecoeur H: Nuclear apoptosis detection by flow cytometry: Influence of endogenous endonucleases. Exp Cell Res 277: 1-14, 2002.

26. Prochazka L, Tesarik R and Turanek J: Regulation of alternative splicing of CD44 in cancer. Cell Signal 26: 2234-2239, 2014.

27. Cao Q, Zhang J, Liu H, Wu Q, Chen J and Chen GQ: The mechanism of anti-osteoporosis effects of 3-hydroxybutyrate and derivatives under simulated microgravity. Biomaterials 35 : 8273-8283, 2014.

28. Manoharan-Valerio M, Ortiz C, Quiñones J, Feliciano G, Diaz A, Rivera D and Castro M: Determination of the $\mathrm{IC}_{50}$ and $\mathrm{LD}_{50}$ of calcium sulfide $(\mathrm{CaS})$ clusters on malignant carcinoma and normal fibroblasts cell lines (LB580). The FASEB Journal 28: LB580, 2014

29. Poff AM, Ari C, Arnold P, Seyfried TN and D'Agostino DP: Ketone supplementation decreases tumor cell viability and prolongs survival of mice with metastatic cancer. Int J Cancer 135: 1711-1720, 2014

30. Eissing N, Heger L, Baranska A, Cesnjevar R, Büttner-Herold M, Söder S, Hartmann A, Heidkamp GF and Dudziak D: Easy performance of 6-color confocal immunofluorescence with 4-laser line microscopes. Immunol Lett 161: 1-5, 2014.

31. Barber HR: Ovarian cancer. CA Cancer J Clin 36: 149-184, 1986.

32. Mueller H and Hahn M: Cytoreductive surgery plus intraperitoneal hyperthermic perfusion in the treatment of recurrent epithelial ovarian cancer: Oral Presentation 00012. Int J Gynecol Cancer 15: 54, 2005 .

33. Koch U, Krause M and Baumann M: Cancer stem cells at the crossroads of current cancer therapy failures-radiation oncology perspective. Semin Cancer Biol 20 116-124, 2010.

34. Shigdar S, Lin J,Li Y, Yang CJ, Wei M, Zhus Y,Liu H and Duan W: Cancer stem cell targeting: The next generation of cancer therapy and molecular imaging. Ther Deliv 3: 227-244, 2012.

35. Espinoza LA, Albanese C and Rodriguez OC: The potential target therapy of prostate cancer stem cells. In: Prostate Cancer - From Bench to Bedside. Spiess PE (eds). InTech, 2011.

36. Scatena R, Bottoni P, Pontoglio A and Giardina B: Cancer stem cells: The development of new cancer therapeutics. Expert Opin Biol Ther 11: 875-892, 2011.

37. Visvader JE and Lindeman GJ: Cancer stem cells in solid tumours: Accumulating evidence and unresolved questions. Nat Rev Cancer 8: 755-768, 2008

38. Clevers H: The cancer stem cell: Premises, promises and challenges. Nat Med 17: 313-319, 2011.

39. Li XX, Wang J, Wang HL, Wang W, Yin XB, Li QW, Chen YY and Yi J: Characterization of cancer stem-like cells derived from a side population of a human gallbladder carcinoma cell line, SGC-996. Biochem Biophys Res Commun 419: 728-734, 2012.

40. Szotek PP, Pieretti-Vanmarcke R, Masiakos PT, Dinulescu DM, Connolly D, Foster R, Dombkowski D, Preffer F, Maclaughlin DT and Donahoe PK: Ovarian cancer side population defines cells with stem cell-like characteristics and mullerian inhibiting substance responsiveness. Proc Natl Acad Sci USA 103: 11154-11159, 2006.

41. Hu L, McArthur C and Jaffe RB: Ovarian cancer stem-like side-population cells are tumourigenic and chemoresistant. $\mathrm{Br}$ J Cancer 102: 1276-1283, 2010

42. Spring FA, Dalchau R, Daniels GL, Mallinson G, Judson PA, Parsons SF, Fabre JW and Anstee DJ: The Ina and Inb blood group antigens are located on a glycoprotein of 80,000 MW (the CDw44 glycoprotein) whose expression is influenced by the In(Lu) gene. Immunology 64: 37-43, 1988. 
43. Ricardo S, Vieira AF, Gerhard R, Leitão D, Pinto R, Cameselle-Teijeiro JF, Milanezi F, Schmitt F and Paredes J: Breast cancer stem cell markers CD44, CD24 and ALDH1: Expression distribution within intrinsic molecular subtype J Clin Pathol 64: 937-946, 2011.

44. Lee CJ, Dosch J and Simeone DM: Pancreatic cancer stem cells. J Clin Oncol 26: 2806-2812, 2008.

45. Du L, Wang H, He L, Zhang J, Ni B, Wang X, Jin H, Cahuzac N, Mehrpour M, Lu Y and Chen Q: CD44 is of functional importance for colorectal cancer stem cells. Clin Cancer Res 14 6751-6760, 2008.

46. Takaishi S, Okumura T, Tu S, Wang SS, Shibata W, Vigneshwaran R, Gordon SA, Shimada Y and Wang TC: Identification of gastric cancer stem cells using the cell surface marker CD44. Stem Cells 27: 1006-1020, 2009.

47. Weng D, Song B, Durfee J, Sugiyama V, Wu Z, Koido S, Calderwood SK and Gong J: Induction of cytotoxic T lymphocytes against ovarian cancer-initiating cells. Int J Cancer 129 1990-2001, 2011.

48. Au A, Aziz Baba A, Goh AS, Wahid Fadilah SA, Teh A, Rosline H and Ankathil R: Association of genotypes and haplotypes of multi-drug transporter genes ABCB1 and ABCG2 with clinical response to imatinib mesylate in chronic myeloid leukemia patients. Biomed Pharmacother 68: 343-349, 2014

49. Sodani K, Patel A, Anreddy N, Singh S, Yang DH, Kathawala RJ, Kumar P, Talele TT and Chen ZS: Telatinib reverses chemotherapeutic multidrug resistance mediated by $\mathrm{ABCG} 2$ efflux transporter in vitro and in vivo. Biochem Pharmacol 89: 52-61, 2014

50. Castillo V, Valenzuela R, Huidobro C, Contreras HR and Castellon EA: Functional characteristics of cancer stem cells and their role in drug resistance of prostate cancer. Int J Oncol 45: 985-994, 2014
51. Yanamoto S, Yamada S, Takahashi H, Naruse T, Matsushita Y, Ikeda H, Shiraishi T, Seki S, Fujita S, Ikeda T, et al: Expression of the cancer stem cell markers CD44v6 and ABCG2 in tongue cancer: Effect of neoadjuvant chemotherapy on local recurrence. Int J Oncol 44: 1153-1162, 2014.

52. El Deeb NM and Abdelzaher E: Stem cell markers OCT4 and nestin in laryngeal squamous cell carcinoma and their relation to survivin expression. Pathol Res Pract 210: 751-758, 2014.

53. Krüger K, Stefansson IM, Collett K, Arnes JB, Aas T and Akslen LA: Microvessel proliferation by co-expression of endothelial nestin and $\mathrm{Ki}-67$ is associated with a basal-like phenotype and aggressive features in breast cancer. Breast 22: 282-288, 2013.

54. Ishiwata T, Matsuda $Y$ and Naito Z: Nestin in gastrointestinal and other cancers: Effects on cells and tumor angiogenesis. World J Gastroenterol 17: 409-418, 2011.

55. Wan G, Zhou L, Xie M, Chen H and Tian J: Characterization of side population cells from laryngeal cancer cell lines. Head Neck 32: 1302-1309, 2010.

56. Dou J, Wen P, Hu W, Li Y, Wu Y, Liu C, Zhao F, Hu K, Wang J, Jiang C, et al: Identifying tumor stem-like cells in mouse melanoma cell lines by analyzing the characteristics of side population cells. Cell Biol Int 33: 807-815, 2009.

57. Zhang JL, Wang Z, Hu W, Chen SS, Lou XE and Zhou HJ: DHA regulates angiogenesis and improves the efficiency of CDDP for the treatment of lung carcinoma. Microvasc Res 87: 14-24, 2013.

58. Fan LM and Li JM: Evaluation of methods of detecting cell reactive oxygen species production for drug screening and cell cycle studies. J Pharmacol Toxicol Methods 70: 40-47, 2014.

59. Matsumoto A and Nakayama KI: Role of key regulators of the cell cycle in maintenance of hematopoietic stem cells. Biochim Biophys Acta 1830: 2335-2344, 2013. 